\title{
Ultrasound-guided adductor canal block using levobupivacaine versus periarticular levobupivacaine infiltration after total knee arthroplasty: a randomized clinical trial
}

\author{
Faruk Cicekci', Ahmet Yildirim", Özkan Önal'", Jale Bengi Celik"', Inci Karav \\ Selçuk Üniversitesi Tıp Fakültesi, Konya, Turkey
}

'MD. Assistant Professor, Department of Anesthesiology, Selçuk Üniversitesi Tıp Fakültesi, Konya, Turkey.

(D) orcid.org/0000-0002-3248-0745

"MD. Assistant Professor, Department of Orthopedics and Traumatology, Selçuk Üniversitesi Tıp Fakültesi, Konya, Turkey. (i) orcid.org/0000-0002-3953-091X

"'MD. Associate Professor, Department of Anesthesiology, Selçuk Üniversitesi Tıp Fakültesi, Konya, Turkey.

(D) orcid.org/0000-0002-5574-1901

"vMD. Professor, Department of Anesthesiology, Selçuk Üniversitesi Tıp Fakültesi, Konya, Turkey.

(D) orcid.org/0000-0003-2167-9967

vMD. Associate Professor, Department of

Anesthesiology, Selçuk Üniversitesi Tıp Fakültesi,

Konya, Turkey.

(D) orcid.org/0000-0001-6546-4277

KEY WORDS:

Levobupivacaine.

Arthroplasty, replacement, knee.

Ultrasonography.

Rehabilitation.

Analgesia.

\begin{abstract}
BACKGROUND: Both postoperative pain control and range of motion are important in total knee arthroplasty (TKA). However, in the literature, there is little comparison of peripheral nerve blocks and periarticular infiltration techniques using levobupivacaine. The aim of our study was to measure pain with visual analogue scale (VAS) and knee range of motion (ROM) between in patients undergoing adductor canal block (ACB) for TKA using levobupivacaine compared to periarticular levobupivacaine infiltration (PAI-L). DESIGN AND SETTING: Prospective randomized clinical trial in a university hospital.

METHODS: Patients aged 40-85 years who underwent unilateral TKA were included; 39 were treated with periarticular infiltration using $40 \mathrm{ml}(0.125 \mathrm{mg})$ of levobupivacaine (PAI-L group); and 40 were treated with ACB using $20 \mathrm{ml}$ of $0.25 \%$ levobupivacaine (ACB-L group). Postoperative pain scores at rest and during active physical therapy were assessed using a VAS, along with knee ROM in flexion and extension. In addition, 100-foot walking time results, total morphine consumption and time of first analgesia requirement were recorded postoperatively.

RESULTS: VAS scores at rest and during active physical therapy and the total amount of morphine consumed were lower in the ACB-L group than in the PAI- $L$ group $(P<0.05)$. In contrast, knee ROM in flexion and extension and 100-foot walking times were greater in the PAI-L group than in the ACB-L group $(P<0.05)$.

CONCLUSION: ACB-L was superior to PAI-L regarding pain treatment after TKA; however, PAI-L was superior to ACB-L regarding postoperative ROM and walking ability.

CLINICAL TRIAL REGISTRY: ACTRN-12618000438257.
\end{abstract}

\section{INTRODUCTION}

Total knee arthroplasty (TKA) is a common surgical procedure that can cause severe postoperative pain. ${ }^{1}$ Various methods for postoperative analgesia management are available, such as systemic opioids, epidural local anesthetic, peripheral nerve block and local anesthetic infiltration analgesia. ${ }^{2}$ Use of systemic opioids can cause adverse effects that may affect functional rehabilitation, such as nausea, vomiting, pruritus, sedation and respiratory depression. ${ }^{3,4}$ Hypotension, urinary retention, and pruritus are more common in patients with epidural analgesia. ${ }^{5}$ In addition, use of long-acting intrathecal opioids causes adverse effects such as bilateral motor block, tremor and hypotension. ${ }^{6}$ Systemic and intrathecal methods for postoperative analgesia are gradually being abandoned because of these negative effects.

Anesthesia management involving multimodal analgesic regimens, including regional anesthesia techniques such as femoral nerve block (FNB) and local infiltration analgesia (LIA), is commonly used for TKA. ${ }^{3,6}$ Although FNB is widely used in TKA, it can cause weakness of the quadriceps muscle and require use of a knee immobilizer, which may prevent early ambulation and can delay discharge. ${ }^{7,8}$

The saphenous nerve is the largest contributor to sensory perception around the knee, while the adductor canal contains the nerve to the vastus medialis, the medial femoral cutaneous nerve, the medial retinacular nerve, articular branches from the posterior division of the obturator nerve and occasionally the anterior branch of the obturator nerve. ${ }^{910}$ Although adductor canal block (ACB) can contribute towards motor blockade of the periarticular musculature, its effect on functional weakness of the quadriceps has been reported to be minimal, compared with FNB. ${ }^{10,11}$ 
One alternative analgesic technique for TKA is periarticular infiltration (PAI) using local anesthetic. ${ }^{12,13}$ Periarticular infiltration is commonly used because of its simplicity, but its efficacy for diminishing postoperative pain after TKA is a matter of controversy. ${ }^{14,15}$

\section{OBJECTIVE}

The primary aim of this study was to compare postoperative pain scores from periarticular infiltration using levobupivacaine (PAI-L) and ultrasound-guided adductor canal block using levobupivacaine (ACB-L). Its secondary aims were to compare knee ROM, total morphine consumption and a 100-foot walking test data among patients undergoing elective unilateral TKA.

\section{METHODS}

This randomized clinical study was reviewed and approved by the Necmettin Erbakan University, Medical Faculty Ethics Committee (reference no. 27.09.2017/146) and was registered in the Australian New Zealand Clinical Trial Registry: ACTRN12618000438257. After obtaining the participants' written informed consent, 94 patients aged 40-85 years whose American Society of Anesthesiologists (ASA) status was I-III and who had been scheduled to undergo unilateral TKA to treat degenerative joint disease were enrolled in the study.

The exclusion criteria were ASA status IV-V, age under 40 years or over 85 years, presentation of chronic pain syndrome or neuropathic pain, morbid obesity, presence of coagulation disorder, inability to walk without help due to known knee disease, and presence of allergic reactions to the medications used in the study. Another exclusion criterion was initially set as consumption of more than $5 \mathrm{mg}$ /day of oral morphine or equivalent opioids. However, this was subsequently changed (after study registration) because patients did need larger amounts of morphine, so this ceased to be a reasonable exclusion criterion. Therefore, even patients consuming larger amounts of morphine were analyzed in this study.

Participants who were eligible for inclusion in the study were identified from the records before the date of the orthopedic surgery. During the preoperative anesthesia examination, these patients were interviewed. They were invited to participate in the study and they filled out an informed consent form.

A computer-generated randomization sequence was prepared by our statisticians. Each study patient was assigned a study number. To avoid loss of concealment, the group to which each patient was allocated could only be accessed by the researchers after each patient had been registered for surgery. However, since the study groups included analgesia applied in different manners (ACB and PAI), the data thus collected could not be blinded. Two anesthetists performed ACB and PAI, while two other anesthetists collected the data.

\section{Anesthesia and surgical technique}

The patients were admitted to the operating room without any premedication. Spinal anesthesia was administered by means of a 22-gauge spinal needle (Atraucan, Braun Germany), consisting of $15 \mathrm{mg}$ ( $3 \mathrm{ml}$ ) of $0.5 \%$ spinal bupivacaine (Marcaine, Abbott Laboratories, Chicago, IL, USA) to each patient after both ACB and PAI. All operations were performed by the same surgical team using a similar technique.

\section{Intervention in the ACB-L group}

Ultrasound-guided ACB was performed using a linear probe (10$18 \mathrm{MHz}$ ) (Esaote MyLab 30 US, Florence, Italy). The probe was placed midway between the inguinal ligament and the medial condyle of the knee under aseptic conditions, with the patient in the supine position, the knee slightly externally rotated and the leg outstretched (frog-leg position). An ultrasonographic image of the saphenous nerve was captured in the adductor canal, laterally to the femoral artery under the sartorius muscle. After negative aspiration, $20 \mathrm{ml}$ of $0.25 \%$ levobupivacaine (Chirocaine, Abbott, Elverum, Norway) was administered into the nerve sheath using a 20 -gauge, 100 -mm, sloped, Teflon-coated unipolar needle (Stimuplex Ultra 360, B. Braun, Melsungen, Germany). The spreading of the local anesthetic spread in the adductor canal was viewed using ultrasonography.

\section{Intervention in the PAI-L group}

A total of $40 \mathrm{ml}(0.125 \mathrm{mg})$ of levobupivacaine was infiltrated into the posterior capsule, femur and tibia, medially and laterally to the joint capsule; and into the quadriceps tendon, vastus medialis obliquus, patellar tendon and dermal-epidermal junction.

\section{Postoperative protocol}

Each patient received $50 \mathrm{mg}$ of IV dexketoprofen (Arveles, Ufsa, Istanbul, Turkey) in the recovery room. Use of a patient-controlled analgesia (PCA) device for morphine delivery was started, and morphine consumption was recorded at 24 and 48 hours. Antibiotic prophylaxis was continued, consisting of $3 \times 1 \mathrm{~g}$ cefazolin (Cefozin, Bilim, Istanbul, Turkey) for 24 hours. The patients were given dexketoprofen every 12 hours and a $1 \mathrm{~g}$ paracetamol tablet (Paranox, Sanofi, Istanbul, Turkey) every 8 hours until discharge. Twenty milligrams of IV metoclopramide (Metpamid, Recordati, Istanbul, Turkey) was given only to patients with nausea and vomiting. All patients were fitted with a knee immobilizer between 12 and 24 hours after the operation, until quadriceps muscle function was restored. Physical therapy was started 24 hours after surgery. Use of a continuous passive motion machine (CPM) (Kinetec, Smith \& Nephew, Memphis, TN, USA) in a room in the orthopedic department was started with an initial setting of 45 degrees. CPM was used to the patients on 
the second postoperative day, for two-hour periods. The patients were also encouraged to starting on active motion of the knee.

\section{Clinical evaluation}

Sociodemographic and clinical data such as age, sex, weight, height, body mass index (BMI), ASA status, side operated, length of operation and duration of tourniquet use were recorded. Pain levels at rest and during active physical therapy were recorded during the preoperative period, 30 minutes after the operation and 2, 6, 12, 24, 36 and 48 hours after the operation, according to scores on a visual analogue scale (VAS). Postoperative maximal ranges of flexion and extension on the $1^{\text {st }}, 2^{\text {nd }}$ and $7^{\text {th }}$ days, and in the $2^{\text {nd }}$ and $6^{\text {th }}$ weeks, were also recorded. In addition, total morphine consumption and a 100-foot walking test data during the preoperative period, at 24 and 48 hours after the operation and at the time of the first requirement for analgesic were recorded.

The sample size calculation was based on a pilot study that we conducted on sixteen patients (whose data were not included in the present study). In this prior study, the mean difference and standard deviation (SD) of the VAS scores 24 hours after the operation between the ACB and PAI groups were 0.40 and 0.19 , respectively. From this, it was determined that 39 subjects would be required to reach an a value of 0.05 and a power of $85 \%$. Moreover, based on data from a retrospective study by Perlas et al., ${ }^{16}$ the primary outcome SD was assumed to be approximately 3.0. It was estimated that the attrition rate due to canceled surgery or reasons of late patient ineligibility could be up to $20 \%$ and, therefore, to account for this, the final sample size selected was $\mathrm{n}=94$ ( 47 per group).

The statistical analyses in this study were performed using the Statistical Package for the Social Sciences (SPSS) 20.0 software. Continuous variables were presented in the form of mean \pm standard deviation or error. The Kolmogorov-Smirnov normality test was used to assess continuous variables. Group comparisons on the variables that showed normal distribution were performed using one-way analysis of variance. Mann-Whitney $U$ variance analysis was used for discrete numerical variables that did not show normal distribution. Relationships between the categorical variables were determined by preparing crosstabs and using the chi-square $\left(\chi^{2}\right)$ test. $\mathrm{P}<0.05$ was accepted as statistically significant.

\section{RESULTS}

A total of 94 patients underwent elective unilateral TKA procedures between March 2017 and September 2017. A total of 14 patients were excluded for the following reasons: age over 85 years $(\mathrm{n}=3)$; delay in admission to subacute rehabilitation $(\mathrm{n}=3)$; admission to the intensive care unit because of respiratory failure $(\mathrm{n}=1)$; bilateral TKA was performed (4); and not wishing to participate $(\mathrm{n}=3)$. Thus 80 patients were enrolled. One patient in the PAI group was further lost to follow-up because of non-attendance at follow-ups, and was therefore not included in the study analysis. Detailed information on enrollment of patients into the study is depicted in the CONSORT flow diagram in Figure 1. The patients' demographic profiles and clinical characteristics were similar $(\mathrm{P}>0.05)$ (Table 1).

Over the first 48 postoperative hours, the VAS data at rest (mean \pm standard error) for the ACB-L and PAI-L groups respectively were as follows: at $30 \mathrm{~min}$, VAS $0.30 \pm 0.08$ and $1.38 \pm 0.10$ $(\mathrm{P}<0.001)$; at $2^{\text {nd }}$ hour, VAS $0.58 \pm 0.11$ and $1.35 \pm 0.10(\mathrm{P}<0.001)$; at $6^{\text {th }}$ hour, VAS $1.08 \pm 0.11$ and $1.92 \pm 0.09(\mathrm{P}<0.001)$; at $12^{\text {th }}$ hour, VAS $1.80 \pm 0.14$ and $2.38 \pm 0.15(\mathrm{P}=0.012)$; at $24^{\text {th }}$ hour, VAS 2.30 \pm 0.16 and $2.80 \pm 0.12(\mathrm{P}=0.028)$; at $36^{\text {th }}$ hour, VAS $1.80 \pm 0.10$ and $2.35 \pm 0.12(\mathrm{P}=0.002)$; and at $48^{\text {th }}$ hour, VAS $2.00 \pm 0.17$ and $2.55 \pm 0.12(\mathrm{P}=0.016)$ (Figure 2).

Over the first 48 postoperative hours, the VAS data with activity (mean \pm standard error) for the ACB-L and PAI-L groups respectively were as follows: at $30 \mathrm{~min}$, VAS $0.98 \pm 0.09$ and $2.40 \pm 0.13$ $(\mathrm{P}<0.001)$; at $2^{\text {nd }}$ hour, VAS $0.95 \pm 0.11$ and $2.25 \pm 0.13(\mathrm{P}<0.001)$; at $6^{\text {th }}$ hour, VAS $1.85 \pm 0.13$ and $2.52 \pm 0.17(\mathrm{P}=0.008)$; at $12^{\text {th }}$ hour, VAS $2.25 \pm 0.15$ and $2.80 \pm 0.15(\mathrm{P}=0.022)$; at $24^{\text {th }}$ hour, VAS 2.70 \pm 0.15 and $3.20 \pm 0.14(\mathrm{P}=0.027)$; at $36^{\text {th }}$ hour, VAS $1.93 \pm 0.19$ and $2.43 \pm 0.12(\mathrm{P}=0.039)$; and at $48^{\text {th }}$ hour, VAS $1.83 \pm 0.17$ and $2.43 \pm 0.12(\mathrm{P}=0.025)$ (Figure 3$)$.

With the exceptions of the preoperative scores and the postoperative $2^{\text {nd }}$ and $6^{\text {th }}$ week scores, the ACB-L group had less range of flexion and extension than the PAI-L group on the $1^{\text {st }}, 2^{\text {nd }}$ and $7^{\text {th }}$ days after surgery. There were significant differences in range of flexion and extension between the groups $(\mathrm{P}<0.05)$ (Table 2).

Differently to the preoperative measurements, the time taken to perform the 100 -foot walking test was significantly longer in the ACB-L group than in the PAI-L group at 24 and 48 hours postoperatively $(218.9 \pm 33.9$ versus $192.2 \pm 24.6 \mathrm{sec}$ and $139.8 \pm 19.5$ versus $112.0 \pm 16.4$ seconds, respectively; $\mathrm{P}<0.001$ ) (Table 2).

The total morphine consumption was significantly lower in the ACB-L group than in the PAI-L group at 48 hours postoperatively $(21.9 \pm 8.9$ versus $33.0 \pm 9.5 \mathrm{mg} ; \mathrm{P}<0.001)$ (Table 3$)$. The times of first requirement for analgesia in the ACB-L and PAI-L groups were $405.3 \pm 41.0$ and $316.7 \pm 36.3$ minutes, respectively. The difference between the groups was significant $(\mathrm{P}<0.001)$ (Table 3).

\section{DISCUSSION}

In the present study, the ACB-L group had better postoperative analgesia both at rest and during active mobilization, compared with the PAI-L group over the first 48 hours after elective unilateral TKA. In addition, less morphine consumption was seen in the ACB-L group. However, during the first week, we found that the PAI-L group presented better flexion and extension knee movements. Moreover, the PAI-L group achieved better results in the walking test than did the ACB-L group. A number of studies 


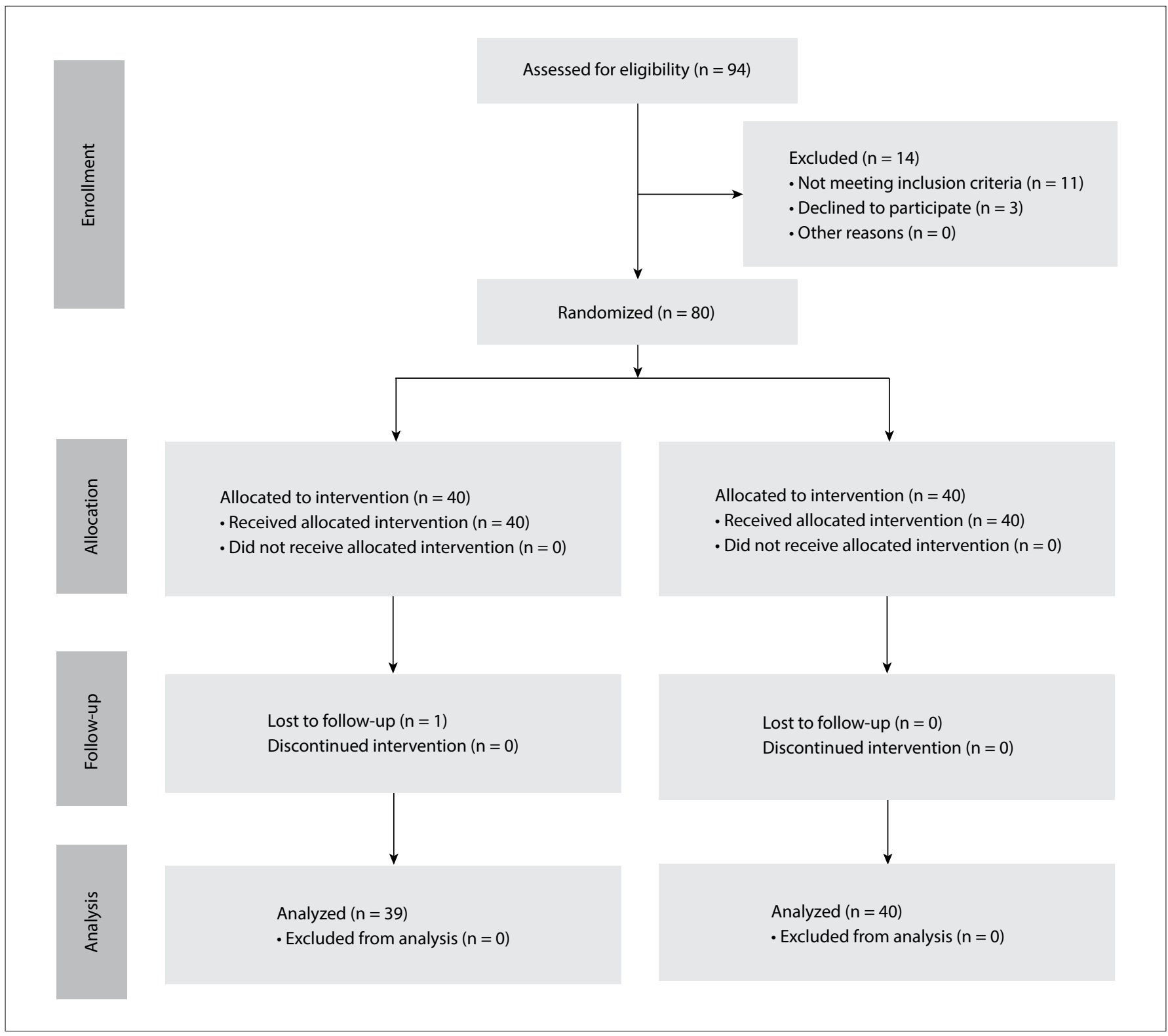

Figure 1. CONSORT flowchart diagram. ACB-L, adductor canal block using levobupivacaine; PAI-L, periarticular infiltration using levobupivacaine.

Table 1. Patients' characteristics

\begin{tabular}{|c|c|c|c|}
\hline & $\begin{array}{c}\text { ACB-L group } \\
n=39\end{array}$ & $\begin{array}{c}\text { PAI-L group } \\
n=40\end{array}$ & $\mathbf{P}$ \\
\hline Age (years) & $69.1 \pm 7.3$ & $68.5 \pm 7.5$ & 0.697 \\
\hline Gender (F/M) & $28 / 12$ & $30 / 10$ & 0.710 \\
\hline Height (cm) & $165.9 \pm 6.5$ & $165.7 \pm 6.4$ & 0.904 \\
\hline BMI $\left(\mathrm{kg} / \mathrm{m}^{2}\right)$ & $32.5 \pm 1.2$ & $32.0 \pm 0.4$ & 0.917 \\
\hline Duration of surgery (minutes) & $82.3 \pm 16.9$ & $84.9 \pm 14.8$ & 0.489 \\
\hline Duration of tourniquet use (minutes) & $89.0 \pm 16.6$ & $90.8 \pm 19.6$ & 0.532 \\
\hline
\end{tabular}

Values are presented as mean \pm standard deviation or number of patients. ACB- $\mathrm{L}=$ adductor canal block using levobupivacaine; PAI- $\mathrm{L}=$ periarticular infiltration using levobupivacaine; F/M = female/male; BMI = body mass index; ASA (I/II/III) = American Society of Anesthesiologists status grade I/II/III R/L = right/left. 


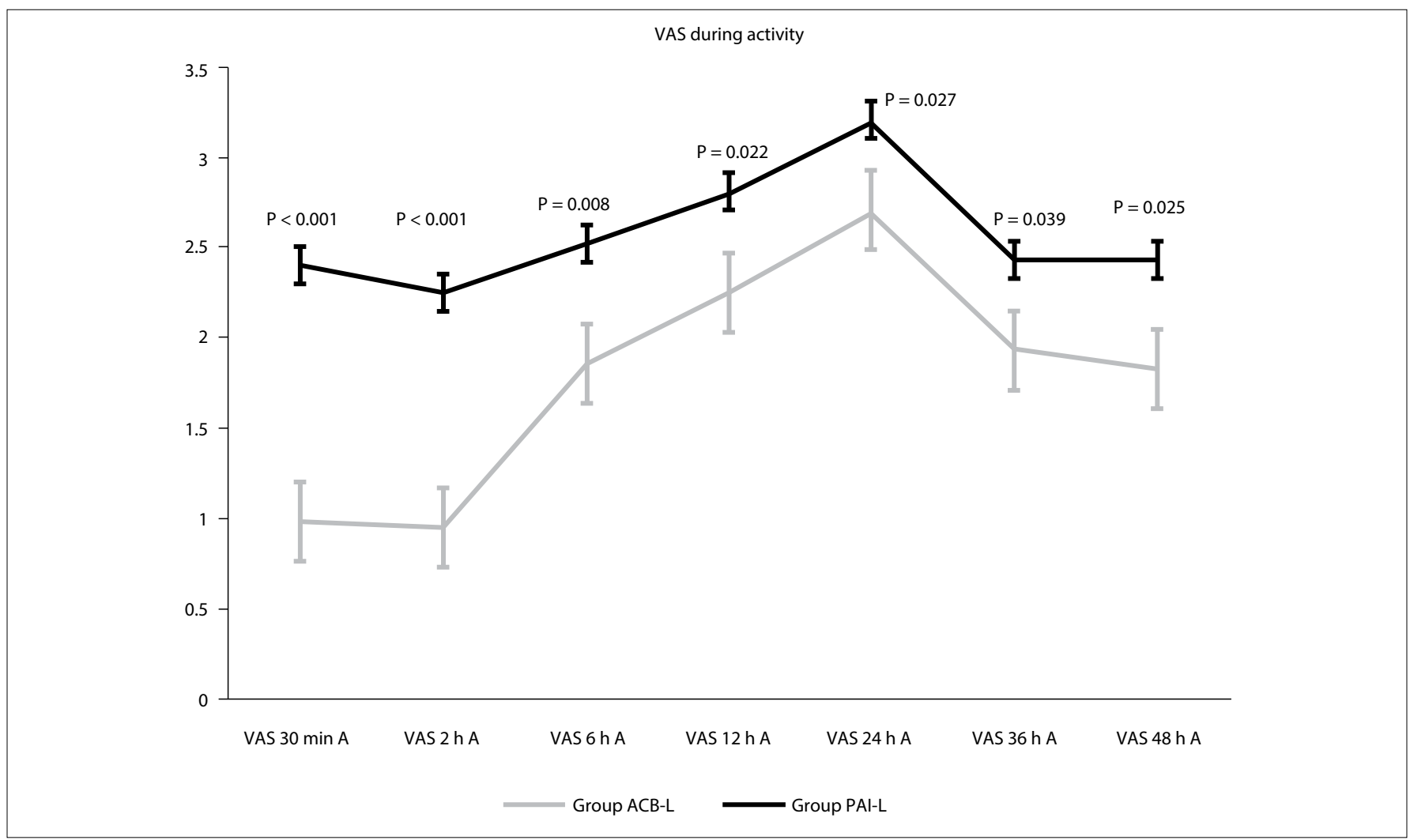

Figure 2. Comparison of postoperative visual analogue scale (VAS) scores during activity (A) between the two groups. There were statistical differences in VAS scores at all time points.

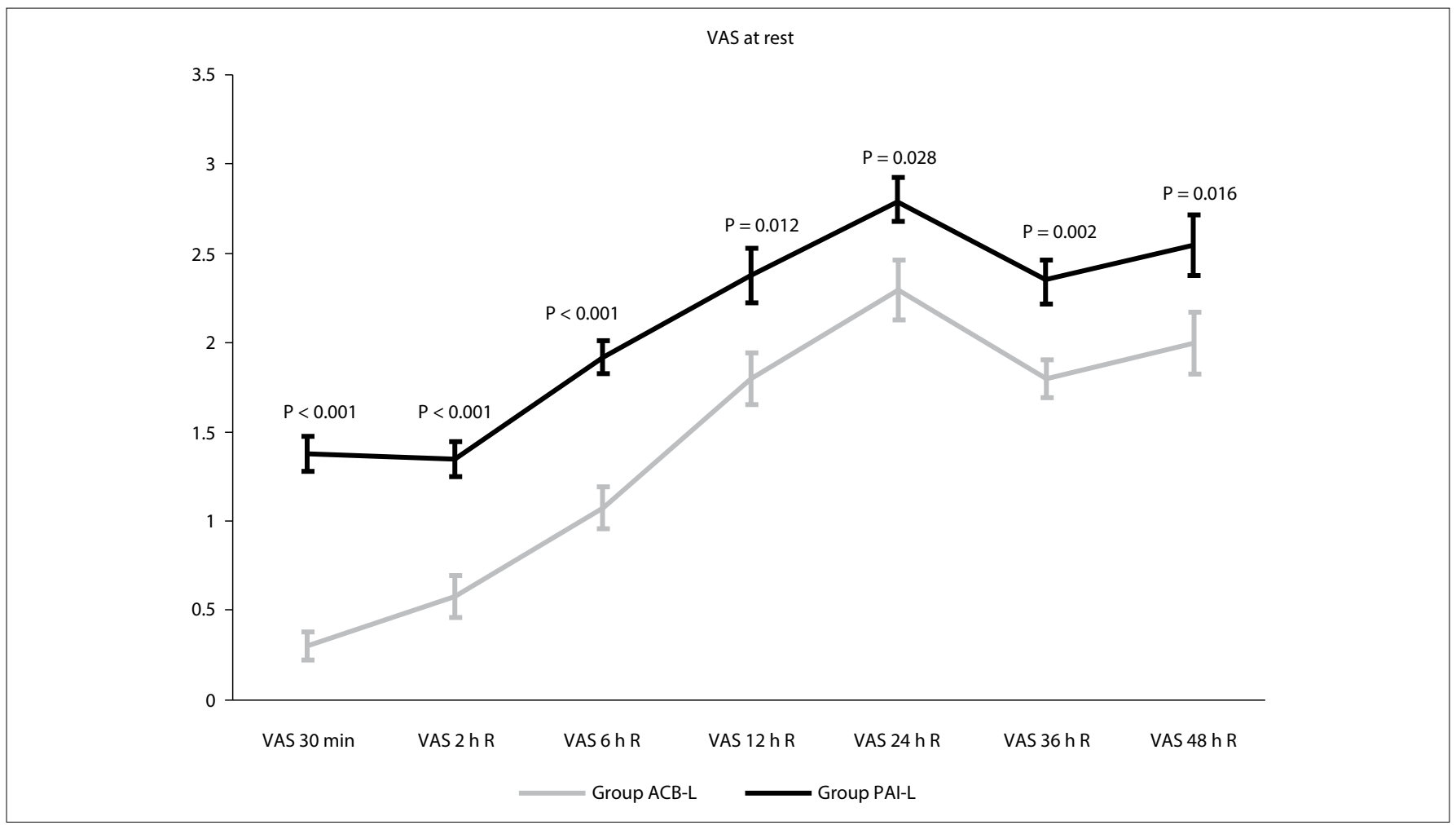

Figure 3. Comparison of postoperative visual analogue scale (VAS) scores at rest (R) between the two groups. There were statistical differences in VAS scores at all time points. 
have compared use of PAI and nerve block by means of local anesthetic agents for pain control in TKA, ${ }^{2,6,17}$ but our study was the first to use levobupivacaine in comparing ACB and PAI.

The adductor canal contains several nerve branches that supply sensory innervations to the knee. These nerve branches consistently include the saphenous nerve (which innervates the infrapatellar skin and the anterior knee capsule) and a distal branch of the motor nerve to the vastus medialis (which provides sensory innervation to the superomedial aspect of the knee and the knee capsule).${ }^{16}$ Ultrasound-guided ACB is used as a theoretical alternative to FNB because the latter has adverse effects such as quadriceps weakness, lack of early ambulation and limitation of physical therapy. With ACB, a rather pure sensory block is obtained instead of the motor block on the knee, while equivalent pain control is achieved..$^{9,18}$

Periarticular local infiltration of anesthetic is one of the most important procedures in multimodal pain control protocols. ${ }^{19}$
This analgesic technique has been specially developed to provide early mobilization and discharge, to avoid sedation and to facilitate rapid physiological recovery after lower-limb arthroplasty. Contrary to femoral nerve block, periarticular infiltration does not inhibit quadriceps function and, at the same time, it reaches the posterior capsule of the knee joint.

Chaumeran et al. conducted a study on FNB and PAI using bupivacaine. They found that the VAS scores and ROM values at rest and in movement were similar, but that PAI gave better results than FNB over the walking distance. ${ }^{20}$

In recent studies on liposomal bupivacaine, the VAS scores, total morphine consumption and ROM values were found to be similar in the PAI and FNB groups until the $48^{\text {th }}$ postoperative hour. ${ }^{17,21,22}$ Yu et al. showed that FNB using liposomal bupivacaine provided better analgesia but less walking distance than did PAI. ${ }^{23}$

In a variety of studies that compared use of ropivacaine for $\mathrm{ACB}$ and PAI, the VAS scores at rest and during activity, the

Table 2. Range of motion (ROM) in flexion and extension and time taken to perform 100-foot walking test before the operation and at different times after the operation, compared between the two groups

\begin{tabular}{|c|c|c|c|}
\hline & $\begin{array}{c}\text { ACB-L group } \\
n=39\end{array}$ & $\begin{array}{c}\text { PAI-L group } \\
n=40\end{array}$ & $\mathbf{P}$ \\
\hline \multicolumn{4}{|c|}{ Range of motion in flexion (degrees) } \\
\hline Preoperative & $109.2 \pm 6.9$ & $108.5 \pm 6.7$ & 0.625 \\
\hline $2^{\text {nd }}$ day & $64.3 \pm 6.2$ & $86.3 \pm 10.9$ & $<0.001$ \\
\hline $1^{\text {st }}$ week & $96.2 \pm 7.7$ & $104.7 \pm 11.9$ & $<0.001$ \\
\hline \multicolumn{4}{|c|}{ Range of motion in extension (degrees) } \\
\hline Preoperative & $4.3 \pm 3.2$ & $4.5 \pm 3.3$ & 0.866 \\
\hline Postoperative $1^{\text {st }}$ day & $11.0 \pm 3.6$ & $8.3 \pm 3.0$ & 0.001 \\
\hline $2^{\text {nd }}$ day & $9.2 \pm 2.6$ & $4.8 \pm 2.1$ & $<0.001$ \\
\hline $1^{\text {st }}$ week & $4.2 \pm 2.4$ & $1.2 \pm 2.1$ & $<0.001$ \\
\hline Postoperative $24^{\text {th }}$ hour & $218.9 \pm 33.9$ & $192.2 \pm 24.6$ & $<0.001$ \\
\hline Postoperative $48^{\text {th }}$ hour & $139.8 \pm 19.5$ & $112.0 \pm 16.4$ & $<0.001$ \\
\hline
\end{tabular}

Values are presented as mean \pm standard error.

ACB-L = adductor canal block using levobupivacaine; PAI-L = periarticular infiltration using levobupivacaine.

Table 3. Time that elapsed until first requirement for analgesia and the total amount of morphine consumed over the first 48 hours after surgery

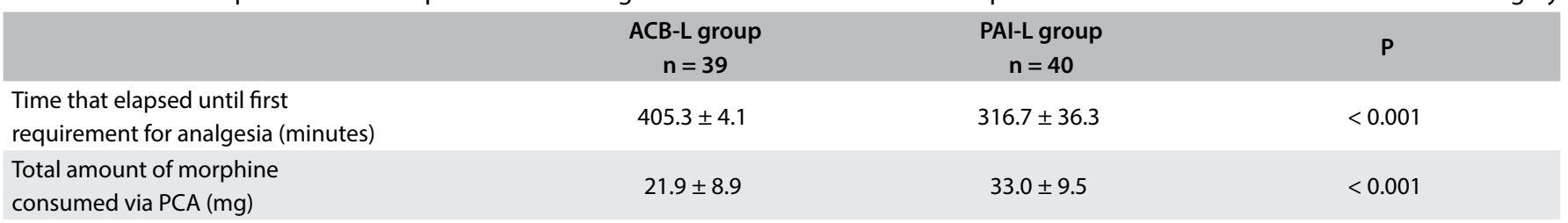

Values are presented as means \pm standard deviation.

ACB-L = adductor canal block using levobupivacaine; PAI-L = periarticular infiltration using levobupivacaine; PCA = patient-controlled analgesia. 
morphine consumption and the walking distance results were similar in the two groups until 48 hours postoperatively. ${ }^{16,24}$ In contrast to the studies of Perlas et al. ${ }^{16}$ and Sawhey et al. ${ }^{24}$, our study found that the total morphine consumption was significantly lower than the ACB-L group at 48 hours postoperatively. In a study by $\mathrm{Li}$ et al. that compared three groups (ACB, FBN and PAI), these authors reported that the VAS values were the same at rest and during movement between the three groups, and that ACB and PAI were also the same in terms of muscle strength. ${ }^{25}$

Levobupivacaine is the S (-) enantiomer of bupivacaine, with less cardiac toxicity and motor block than bupivacaine, but longer duration of action. ${ }^{26}$ Kovalak et al. reported that use of continuous femoral nerve block (CFNB) gave rise to superior VAS scores at rest and during activity, better passive and active ROM, lower total opioid consumption and better two-minute walking test results than did use of PAI. ${ }^{27}$ However, in their study, levobupivacaine infiltration was administered to the knee joint capsule of all patients in both groups. In a study by Wall et al., ${ }^{28}$ it was reported that the effects of levobupivacaine for FNB and PAI on postoperative VAS values were similar. The authors ${ }^{28}$ showed that ACB gave rise to better VAS scores at rest and during activity than did FNB, over the first 48 postoperative hours.

Preoperative range of motion is the biggest indicator of postoperative range of motion. Many factors determine the range of motion after surgery. Rehabilitation programs after total knee arthroplasty should not be halted until at least $90^{\circ}$ of knee flexion has been achieved, so that patients can resume normal social life. ${ }^{29}$ Ritter et al. found that age, preoperative range of motion, intraoperative range of motion and posterior capsule relaxation during surgery were important. They explained that after the first year, there was no further effect on the degree of flexion from the passage of time, and that the range of motion acquired in the first six months was important. ${ }^{30}$ Consequently, after knee prosthetic surgery, the preoperative range of motion, the degree of relaxation of the posterior capsule during surgery, the patient's age and the etiology of osteoarthritis take on importance.

The ability of a patient to perform functional activities, such as walking, rising from a chair and climbing stairs, depends on sufficient postoperative knee ROM. Isometric quadriceps exercises are started on the first postoperative day in our service. Knee ROM exercises for the first 3 days $0-30^{\circ}$ flexion, at least $90^{\circ}$ knee flexion between days. ${ }^{31} \mathrm{~A}$ meta-analysis on the range of knee flexion that compared use of periarticular local infiltration with FNB did not find any significant difference between these two groups. ${ }^{32}$ However, another meta-analysis suggested that post-TKA patients who underwent $\mathrm{ACB}$ showed better outcomes regarding ROM than did those who underwent FNB, throughout the first $72 \mathrm{~h}$ (i.e. post-anesthesia and after 24, 48 and 72 hours). ${ }^{33}$ This latter meta-analysis showed that PAI provided better flexion and extension ROM values postoperatively on the $1^{\text {st }}$ and $2^{\text {nd }}$ days and after the $1^{\text {st }}$ week than $\operatorname{did} \mathrm{ACB}^{34}$.

According to the common milestones used in relation to TKA treatments, patients who can walk 100 feet ( $=30.48$ meters) with an assistive device, go to the toilet, make transfers, perform basic daily activities and do home exercise programs independently are in a condition in which they can be discharged home. In the present study, the results from 100-feet walking tests over the first 48 postoperative hours were better with use of PAI than with use of ACB. A placebo-controlled randomized trial on ACB suggested that administration of ropivacaine into the adductor canal provided effective analgesia, such that it significantly reduced pain and improved postoperative mobility, compared with placebo. ${ }^{24}$

In our study, we found that the VAS scores were better and the total amount of morphine consumed was lower in the ACB-L group than in the PAI group. However, the ROM data and walking results were shown to be superior in the PAI-L group. These results can be explained by the blocking of the saphenous nerve in the adductor canal through use of levobupivacaine over the first 48 hours after the operation. However, a possible attenuating effect on quadriceps muscle strength from ACB also accounts for the knee ROM results and the walking results in the PAI-L group. ${ }^{34,35}$

The main limitation of the current study was the inability to blind both the participants and the physicians to comparisons between peripheral nerve blockade and periarticular injection. This lack of blindness may have introduced some risk of bias from both the patients and the physicians. The outcome assessments from the adjudicators and all the statistical analyses were conducted in a blinded manner. In addition, the impossibility of measuring quadriceps muscle power before and after the operation using special instruments was another limitation. If this had been possible, the evaluation between the ACB-L and the PAI-L groups could have been more objective.

\section{CONCLUSION}

This randomized clinical trial found that after total knee arthroplasty, ultrasound-guided adductor canal block with levobupivacaine was associated with shorter time taken to perform 100-foot walking test (24 hours post-operatively) and lower post-operative consumption of morphine when compared to periarticular infiltration with levobupivacaine. However, no difference between these interventions was found for range of knee motion after six weeks, pain at rest after 48 hours and pain during activities after 48 hours. 


\section{REFERENCES}

1. Wylde V, Rooker J, Halliday L, Blom A. Acute postoperative pain at rest after hip and knee arthroplasty: severity, sensory qualities and impact on sleep. Orthop Traumatol Surg Res. 2011;97(2):139-44. PMID: 21388906; doi: 10.1016/j.otsr.2010.12.003.

2. Mahadevan D, Walter RP, Minto G, et al. Combined femoral and sciatic nerve block vs combined femoral and periarticular infiltration in total knee arthroplasty: a randomized controlled trial. J Arthroplasty. 2012;27(10):1806-11. PMID: 22770852; doi: 10.1016/j. arth.2012.05.018

3. Chinachoti T, Nilrat P, Samarnpiboonphol P. Nausea, vomiting and pruritus induced by intrathecal morphine. J Med Assoc Thai. 2013;96(5):589-94. PMID: 23745315.

4. Singelyn FJ, Deyaert M, Joris D, Pendeville E, Gouverneur JM. Effects of intravenous patient-controlled analgesia with morphine, continuous epidural analgesia, and continuous three-in-one block on postoperative pain and knee rehabilitation after unilateral total knee arthroplasty. Anesth Analg. 1998;87(1):88-92. PMID: 9661552.

5. Fowler SJ, Symons J, Sabato S, Myles PS. Epidural analgesia compared with peripheral nerve blockade after major knee surgery: a systematic review and meta-analysis of randomized trials. $\mathrm{Br} J$ Anaesth. 2008;100(2):154-64. PMID: 18211990; doi: 10.1093/bja/aem373.

6. Safa B, Gollish J, Haslam L, McCartney JC. Comparing the effects of single shot sciatic nerve block versus posterior capsule local anesthetic infiltration on analgesia and functional outcome after total knee arthroplasty: a prospective, randomized, double-blinded, controlled trial. J Arthroplasty. 2014;29(6):1149-53. PMID: 24559684; doi: 10.1016/j. arth.2013.11.020.

7. Jaeger P, Nielsen J, Henningsen MH, et al. Adductor canal block versus femoral nerve block and quadriceps strength; a randomized, doubleblind, placebo-controlled, crossover study in healthy volunteers. Anesthesiology. 2013;118(2):409-15. PMID: 23241723; doi: 10.1097/ ALN.0b013e318279fa0b.

8. Berend ME, Berend KR, Lombardi AV Jr. Advances in pain management. Bone Joint J. 2014;96-B(11 Supple A):7-9. PMID: 25381400; doi: 10.1302/0301-620X.96B11.34514.

9. Lund J, Jenstrup MT, Jaeger P, Sørensen AM, Dahl JB. Continuous adductor-canal-blockade for adjuvant post-operative analgesia after major knee surgery: preliminary results. Acta Anaesthesiol Scand. 2011;55(1):14-9. PMID:21039357; doi: 10.1111/j.1399-6576.2010.02333.x.

10. Shah NA, Jain NP. Is continuous adductor canal block better than continuous femoral nerve block after total knee arthroplasty? Effect on ambulation ability, early functional recovery and pain control: a randomized controlled trial. J Arthroplasty. 2014;29(11):2224-9. PMID: 25041873; doi: 10.1016/j.arth.2014.06.010.

11. Kim DH, Lin Y, Goytizolo E, et al. Adductor canal block versus femoral nerve block for total knee arthroplasty: a prospective, randomized, controlled trial. Anesthesiology. 2014;120(3):540-50. PMID: 24401769; doi: 10.1097/ALN.0000000000000119.
12. Keijsers $R$, van Delft $R$, van den Bekerom MP, et al. Local infiltration analgesia following total knee arthroplasty: effect on post-operative pain and opioid consumption - a meta-analysis. Knee Surg Sports Traumatol Arthrosc. 2015;23(7):1956-63. PMID: 24292980; doi: 10.1007/ s00167-013-2788-1.

13. Teng $Y$, Jiang J, Chen $S$, et al. Periarticular multimodal drug injection in total knee arthroplasty. Knee Surg Sports Traumatol Arthrosc. 2014;22(8):1949-57. PMID: 23783531; doi: 10.1007/s00167-013-2566-0.

14. Kerr DR, Kohan L. Local infiltration analgesia: a technique for the control of acute postoperative pain following knee and hip surgery: a case study of 325 patients. Acta Orthop. 2008;79(2):174-83. PMID: 18484242; doi: 10.1080/17453670710014950.

15. Fowler SJ, Christelis N. High volume local infiltration analgesia compared to peripheral nerve block for hip and knee arthroplastywhat is the evidence? Anaesth Intensive Care. 2013;41(4):458-62. PMID: 23808503.

16. Perlas A, Kirkham KR, Billing R, et al. The impact of analgesic modality on early ambulation following total knee arthroplasty. Reg Anesth Pain Med. 2013;38(4):334-9. PMID: 23759708; doi: 10.1097/ AAP.0b013e318296b6a0.

17. Horn BJ, Cien A, Reeves NP, Pathak P, Taunt CJ Jr. Femoral Nerve Block vs Periarticular Bupivacaine Liposome Injection after Primary Total Knee Arthroplasty: Effect on Patient Outcomes. J Am Osteopath Assoc. 2015;115(12):714-9. PMID: 26618816; doi: 10.7556/jaoa.2015.146.

18. Kim DH, Lin Y, Goytizolo EA, et al. Adductor canal block versus femoral nerve block for total knee arthroplasty: a prospective, randomized, controlled trial. Anesthesiology. 2014;120(3):540-50. PMID: 24401769; doi: 10.1097/ALN.0000000000000119.

19. Parvataneni HK, Ranawat AS, Ranawat CS. The use of local periarticular injections in the management of postoperative pain after total hip and knee replacement: a multimodal approach. Instr Course Lect. 2007;56:125-31. PMID: 17472300

20. Chaumeron A, Audy D, Drolet P, Lavigne M, Vendittoli PA. Periarticular injection in knee arthroplasty improves quadriceps function. Clin Orthop Relat Res. 2013;471(7):2284-95. PMID: 23516031; doi: 10.1007/ s11999-013-2928-4.

21. Kirkness CS, Asche CV, Ren J, et al. Assessment of liposome bupivacaine infiltration versus continuous femoral nerve block for postsurgical analgesia following total knee arthroplasty: a retrospective cohort study. Curr Med Res Opin. 2016;18:1-10. PMID: 27326760; doi: 10.1080/03007995.2016.1205007.

22. Surdam JW, Licini DJ, Baynes NT, Arce BR. The use of exparel (liposomal bupivacaine) to manage postoperative pain in unilateral total knee arthroplasty patients. J Arthroplasty. 2015;30(2):325-9. PMID: 25282071; doi: 10.1016/j.arth.2014.09.004

23. Yu S, Szulc A, Walton S, Bosco J, Iorio R. Pain Control and Functional Milestones in Total Knee Arthroplasty: Liposomal Bupivacaine Versus Femoral Nerve Block. Clin Orthop Relat Res. 2017;475(1):110-7. PMID: 26883652; doi: 10.1007/s11999-016-4740-4. 
24. Sawhney M, Mehdian H, Kashin B, et al. Pain After Unilateral Total Knee Arthroplasty: A Prospective Randomized Controlled Trial Examining the Analgesic Effectiveness of a Combined Adductor Canal Peripheral Nerve Block with Periarticular Infiltration versus Adductor Canal Nerve Block Alone versus Periarticular Infiltration Alone. Anesth Analg. 2016;122(6):2040-6. PMID: 27028771; doi: 10.1213/ANE.0000000000001210.

25. Li D, Tan Z, Kang P, Shen B, Pei F. Effects of multi-site infiltration analgesia on pain management and early rehabilitation compared with femoral nerve or adductor canal block for patients undergoing total knee arthroplasty: a prospective randomized controlled trial. Int Orthop. 2017;41 (1):75-83. PMID: 27557955; doi: 10.1007/s00264-016-3278-0.

26. McLeod GA, Burke D. Levobupivacaine. Anaesthesia. 2001;56(4):331-41. PMID: 11284819; doi: 10.1046/j.1365-2044.2001.01964.x.

27. Kovalak E, Doğan AT, Üzümcügil O, et al. A comparison of continuous femoral nerve block and periarticular local infiltration analgesia in the management of early period pain developing after total knee arthroplasty. Acta Orthop Traumatol Turc. 2015;49(3):260-6.

28. Wall PD, Sprowson AP, Parsons N, et al. Perioperative Analgesia for Knee Arthroplasty Collaborators. Protocol for a single-centre randomised controlled trial of multimodal periarticular anaesthetic infiltration versus single-agent femoral nerve blockade as analgesia for total knee arthroplasty: Perioperative Analgesia for Knee Arthroplasty (PAKA). BMJ Open. 2015;21;5(12):e009898. PMID: 26692559; doi: 10.1136/ bmjopen-2015-009898.

29. Harvey IA, Barry K, Kirby SP, Johnson R, Elloy MA. Factors affecting the range of movement of total knee arthroplasty. J Bone Joint Surg Br. 1993;75(6):950-5. PMID: 8245090.

30. Ritter MA, Harty LD, Davis KE, Meding JB, Berend ME. Predicting range of motion after total knee arthroplasty. Clustering, long-liner regression and regression tree analysis. J Bone Joint Surg Am. 2003;85-A(7):127885. PMID: 12851353.

31. Mistry JB, Elmallah RD, Bhave A et al. Rehabilitative guidelines after total knee arthroplasty: a review. The journal of knee surgery. 2016:29(03);201217. PMID:26963074 doi: 10.1055/s-0036-1579670.

32. Wang C, Cai XZ, Yan SG. Comparison of Periarticular Multimodal Drug Injection and Femoral Nerve Block for Postoperative Pain Management in Total Knee Arthroplasty: A Systematic Review and Meta-Analysis. J Arthroplasty. 2015;30(7):1281-6. PMID: 25735501; doi: 10.1016/j. arth.2015.02.005.

33. Wang $D$, Yang $Y, L i$, et al. Adductor canal block versus femoral nerve block for total knee arthroplasty: a meta-analysis of randomized controlled trials. Sci Rep. 2017;7:40721. PMID: 28079176; doi: 10.1038/ srep40721.

34. Jenstrup MT, Jæger P, Lund J Bache S, Mathiesen O, Larsen TK, Dahl JB. Effects of adductor canal blockade on pain and ambulation after total knee arthroplasty: a randomized study. Acta Anaesthesiol Scand. 2012;56(3):357-64. PMID:22221014; doi: 10.1111/j.1399-6576.2011.02621.x.
35. Jæger P, Zaric D, Fomsgaard JS, et al. Adductor canal block versus femoral nerve block for analgesia after total knee arthroplasty: a randomized, double-blind study. Reg Anesth Pain Med. 2013;38(6):526-32. PMID: 24121608; doi: 10.1097/AAP.0000000000000015.

\section{Sources of funding: None \\ Conflict of interest: None}

Date of first submission: July 25, 2018

Last received: October 3, 2018

Accepted: December 10, 2018

\section{Address for correspondence:}

Faruk Cicekci

Department of Anaesthesiology, Selçuk University, Medical Faculty

Konya

Alaadin Keykubat Yerleskesi

Tip Fakultesi Selçuklu, Konya, Turkey

Tel. 0090-332-2415000

E-mail: farukcicekci@yahoo.com 